\title{
Application of e-learning in the TEMAP project
}

\author{
Markéta Potůčková, Tomáš Bayer \\ Department of Applied Geoinformatics and Cartography \\ Faculty of Science, Charles University in Prague \\ Albertov 6, 12843 Praha 2, Czech Republic marketa.potuckova@natur.cuni.cz
}

\begin{abstract}
Map collections belong to valuable parts of the cultural heritage of each nation. The TEMAP project focuses on development and utilisation of modern digital technologies for on-line accessibility of map collections as well as their cataloguing and protection. The article introduces the concept of an e-learning course that aims at explanation of methodologies and software tools applied and developed in scope of the project. The main focus is on the modules Georeferencing and Cartometric analysis that comprise description of the on-line tool Georeferencer and free software packages MapAnalyst and detectproj.
\end{abstract}

Keywords: e-learning, TEMAP project, georeferencing, cartometric analysis

\section{Introduction}

Old cartographic works always attracted professionals as geographers, cartographers, surveyors or historians but also general public. Fast development of digital technologies and possibility of accessing scanned maps on the internet have even increased an interest in map collections comprising early cartographic works as well as modern cartographic products. They become important GIS layers in environmental studies (e.g. land use changes, development of settlements), scientific conferences and publications in the field of historical cartography and geography are numerous (e.g. [1], [2], [3]). Contrary to this attention of map users many of map collections lack a thorough evidence of their cartographic works; their funds are not systematically catalogued and digitised.

The project "Technology for Access to Czech Map Collections: methodology and software for protection and re-use of national cartographic heritage" (TEMAP) reflects the needs of memory institutions to process but also protect and make accessible their map collections. By combining knowledge in bibliography, cartography and web technologies the project aims at creating a set of open-source software tools and methodologies that enable processing of old maps and cartographic documents with regard to their cataloguing, cartographic correctness and publishing on the web. The methodology of cataloguing is based on the Resource Description and Access (RDA) rules for cartographic documents published by Joint Steering Committee for RDA in June 2010. The Georeferencer and the detectproj are the main software tools for a map georeferencing and analysis developed within the project and they will be described later in this article. A software solution based on the Geonetwork opensource metadata catalogue, PostgreSQL database system and the MapServer/Geoserver for management, searching, publishing and on-line presentation of cartographic documents in a web application is also one of the project goals. The developed methodologies and software solutions will be tested on selected cartographic works from the map collections of the partners of the TEMAP project - the Moravian Library, Masaryk University in Brno and Charles 
University in Prague. The project started in 2011 and it is planned to be finished in 2015. It is supported by the Czech Ministry of Culture. More information can be found on the project homepage http://www. temap.cz/.

The project outputs are meant to be of benefit of general and professional public. In order to explain the basics of the used technologies and possibilities of their applications, an e-learning course "Old maps - digitizing, cataloguing, analysis" is being designed as a supplement of the project and it is going to be opened for public at the end of 2013. This article first describes a general outline of this course and afterwards it focuses on two of its modules that are related to geoinformatics, namely Georeferencing and Cartometric Analysis.

\section{Contents of the course}

Map collections specialized on early and old cartographic works are nowadays available on the internet, e.g. David Rumsey Map Collection [4], Afriterra [5], the Moravian Library [6] as well as tools for their georeferencing, e.g. MapRectifier [7], WorldMap WARP [8], eHarta [9], Georeferencer [10], and analysis MapAnalyst [11]. Several conferences on cartographic heritage took place in the last decade e.g. [12], [13], [14] and scientific papers on analyses of old maps and their utilization in different projects are numerous. The e-learning part of the TEMAP project combines information from these sources with new methodologies and software tools developed in the scope of the project. It uses the Moodle learning management system [15] as the platform and it is divided into four modules:

- Technology of digitizing old maps

- Principles of cataloguing old maps

- Georeferencing

- Cartometric Analysis

The module Technology for digitizing old maps comprises information on technical requirements on scanners suitable for scanning old maps regarding the type of the scanner, its calibration and testing, resolution and formats of output files. Issues of protecting valuable old prints as well as problems connected with scanning maps from atlases are mentioned. Up-to-date and preferably open-source software tools for creating previews and image tiles usable for on-line publishing are presented. The module is supplemented with examples of solutions utilized in the TEMAP project.

Objectives of the second module are to introduce the Resource Description and Access (RDA) rules applied on cartographic documents and the methodology for cataloguing old maps deposited at the Map Collection of Charles University in Prague. It includes formal descriptors of old maps based on the second edition of Anglo-American Cataloguing Rules (AARC2/R), MARC 21 Format for Bibliographic Data and International Standard Bibliographic Description for Cartographic Materials (ISBD (CM)) [16]. Attention is paid to special features of early maps (extra editions, reprints, scale). Examples of maps that have been already processed and can be searched from the Charles University Centralized Catalogue (http://ckis.cuni.cz) are given.

Modules Georeferencing and Cartometric Analysis are discussed in detail in the following chapters. 


\section{Module Georeferencing}

From the point of view of the TEMAP project, old maps lacking reliable geographic coordinates and scale need to be transformed to a selected georeference system for the purpose of cataloguing (definition of metadata, namely a scale and a map "bounding box") and their cartometric analysis.

The georeferencing module focuses on

- image transformations suitable for old maps,

- selection of identical points,

- available on-line georeferencing tools.

Theoretical bases are explained in a form of a presentation supplemented with articles explaining geometric transformations [17]. Short introduction and links to georeferencing tools such as MapRectifier [7] and WorldMap WARP [8] is given including some technological details. Nevertheless, most attention is paid to the Georeferencer which extension is one of the project goals.

\section{Georeferencer}

This on-line georeferencing tool has been designed and implemented by Klokan Technologies and the team of the Moravian Library [10]. Using OpenLayers technology [18] on a client side, the Georeferencer allows opening a map that has been already published on the web and collecting identical points that can be identified in a reference map as well. On the server side, the map to be georeferenced must be published using tiles (Tile Map Service [19] or Zoomify technology [20]) [21]. The OpenStreetMap is provided as a reference map in the current version of the software. After registration a user can upload a map of interest and start with collecting identical points (Figure 1). The advantage is that the points are saved (including their history) and the georeference of a selected map can be changed or improved at any time. The information about the placement of the map in Mercator projection used in most web applications [22] can be exported as ESRI world file or OGC KML (Google Earth) format. Georeferenced maps can be also visualized in Google Earth (Figure 1). Moreover, a cartometric analysis using the MapAnalyst (see chapter 4) can be also performed on-line. Within the TEMAP project the Georeferencer is going to be extended of some new features such as support for cartographic projections or search for maps by image similarity [16]. After an internal pilot at the Moravian Library and the first public pilot at the National Library of Scotland, the Georeferencer has been recently employed at the British Library for crowdsourcing of spatial metadata capture for two of its most important collections of historic mapping of Britain [23].

\section{Module Cartometric Analysis}

The goal of a cartometric analysis in the TEMAP project is an assessment of planimetric accuracy and estimation of cartographic parameters of old maps (i.e. map projection and its properties). All analyses are based on a set of corresponding 0D-2D elements in the analyzed and reference maps; algorithms use various methods of robust statistics, point pattern 

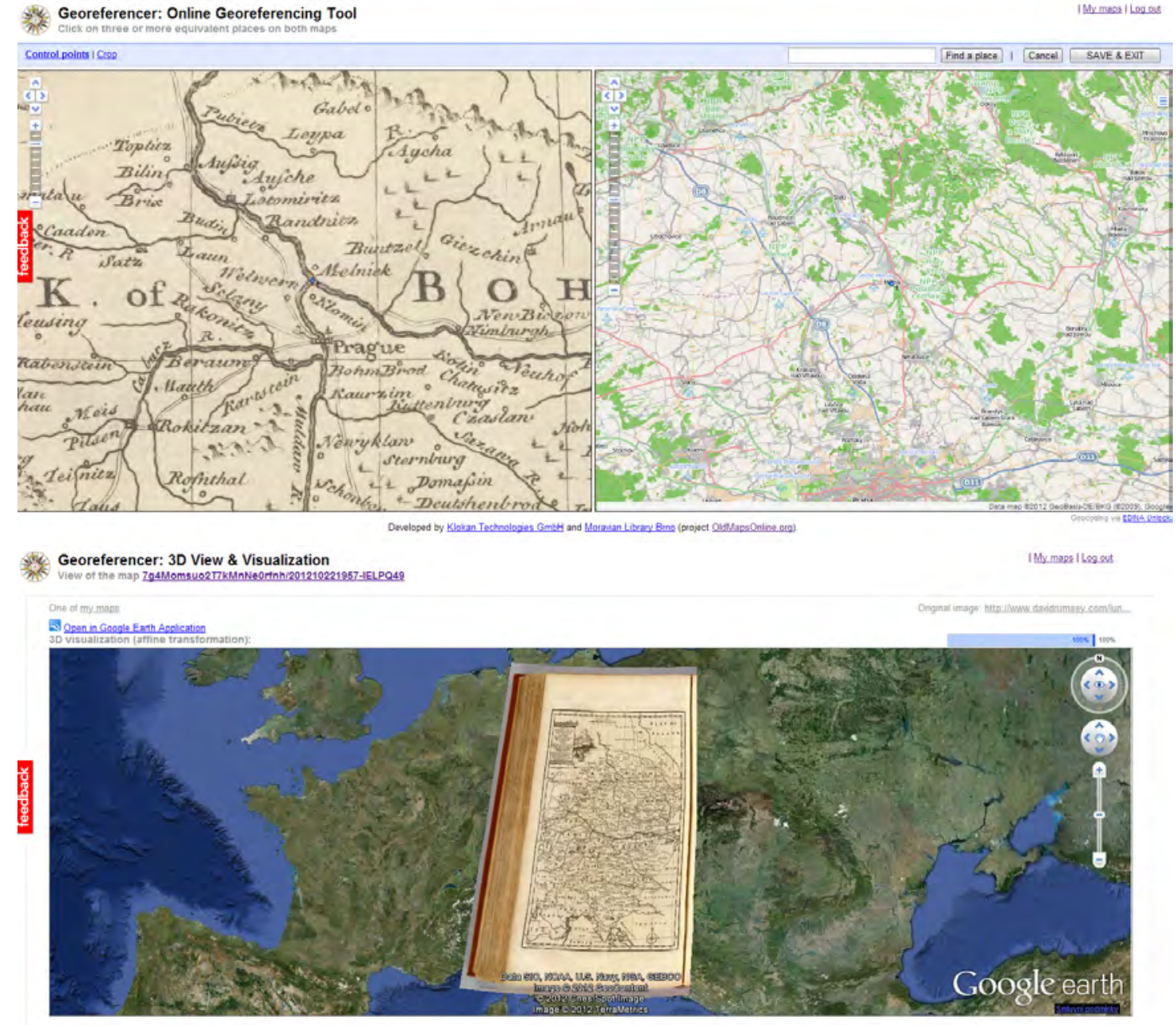

Figure 1: The Georeferencer interface for collecting identical points (up). Example of Emanuel Bowen's map of Germany from 1747 published by W. Innys et al. (David Rumsey Map Collection [4]). Visualisation of the georeferenced map in Google Earth (down).

analysis, shape matching and genetic algorithms. Thus, it is necessary to keep in mind that obtained results are dependent on selection of identical points and their number.

The e-learning module Cartometric Analysis concentrates on following features:

- residuals on identical points,

- positional displacement,

- evaluation of planimetric accuracy,

- determination of the scale,

- analysis of scale in relation to the geographic position,

- analysis of rotation in relation to the geographic position, 
- estimation of the map projection.

Theoretical background and methodology of a possible analysis is explained on examples of previous authors' publications [24], [25]. Two free software solutions for a map analysis are introduced and supplemented with data for their evaluation.

\section{MapAnalyst}

MapAnalyst is a well known and widely applied tool for a cartometric analysis of old maps [26]. It is an open-source Java application developed at the Institute of Cartography ETHZurich with following functions:

- Georeferencing of an early map to a reference map using a set of identical points

- Visualisation of

- distorted graticule

- residuals on identical points

- isolines of scale distortion

- isolines of rotation

Depending on the number of identical points and the geometrical characteristics of evaluated maps, Helmert 4 parameters or affine 5 or 6 parameters transformations can be chosen. Moreover, robust Huber estimator, V-estimator or Hampel estimator can be applied.

The MapAnalyst user interface is very simple and intuitive so the tool is also suitable for users with only basic knowledge in cartography. OpenStreetMap is set as a default reference map but it can be replaced with any georeferenced image file. Identical points can be collected either in the MapAnalyst or can be imported from a text file. Results of the analysis can be exported in several vector (shp, svg, wmf, dxf) and raster (jpeg, png) formats. Figure 2 shows graphical outputs of an analysis of the Map of Bohemia by P. Kaerius (1620) from the MapAnalyst [24].

\section{detectproj}

One of the aims of a cartometric analysis is to identify the cartographic projection used for a map construction. The procedure is usually based on a trial-and-error method [26]. The free software package detectproj [27] enables to detect an unknown map projection and estimate its parameters based on the analysis of a set of corresponding 0D-2D elements measured both in the analysed and the reference maps. Points of the graticule can also be added in order to increase the reliability of the calculation. Due to the fact that early maps are not constructed on solid geometric basis, some of the drawn map elements are highly affected by errors. The detectproj software also contains a utility automatically excluding incorrectly drawn map elements from a further cartometric analysis.

The output parameters are an estimated category of a cartographic projection, the latitude of a true parallel $\varphi_{0}$, true meridian $\lambda_{0}$ and a position of the cartographic pole $\varphi_{q}, \lambda_{q}$. The calculation can be done in the normal, transverse or oblique aspects of the projection. Early maps were created without any geodetic bases and exact geometric procedures therefore it 

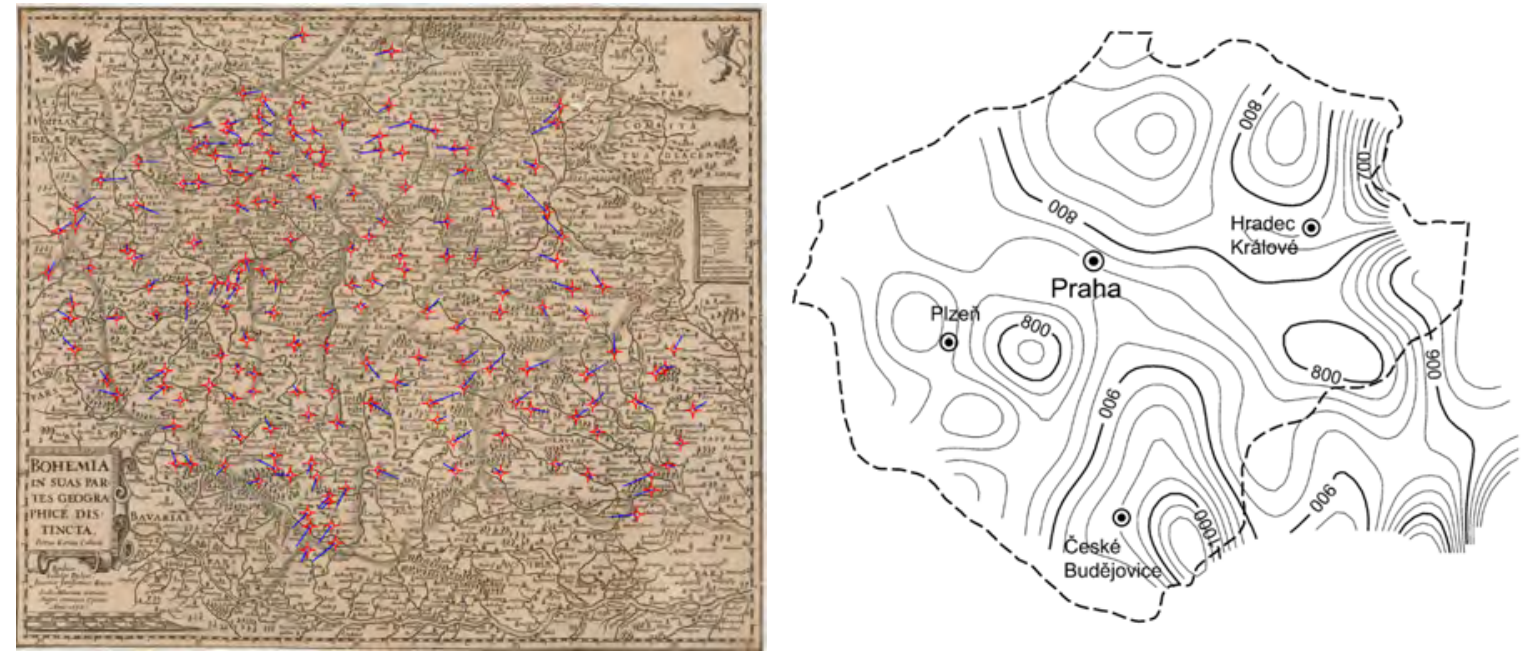

Figure 2: Displacement on identical points (left) and isolines of scale (M/1000) (right) on the Map of Bohemia by P. Kaerius (1620) created in MapAnalyst (the isolines were further processed in ArcGIS) [24]

is impossible (and unreasonable) to identify the cartographic projection. The outputs of the detectproj then have only an orientation value. The software supports 55 cartographic projections but there is an option to add a new projection by editing an input definition file. The output is a text file comprising parameters of an estimated projection and values of the evaluation criteria. The concept and methods of control of the software are similar to the cartographic projection library Proj 4 [28]. However, it includes a new kernel for cartographic computations and analyses. It is available for OS Windows, GNU/Linux and MacOS. [27]

From the point of view of cataloguing of early maps, the detectproj is valuable for obtaining metadata information about the cartographic projection of map sheets. It can be combined with the Georeferencer when collected control points can be used both for the definition of a bounding box of the map and estimation of the cartographic projection.

In comparison to the Georeferencer and the MapAnalyst, the outputs of detectproj are not presented graphically but only in the text format. On the other hand the software offers more sophisticated approach and provides information about criteria used for the estimation of the map projection which requires deeper knowledge in cartography and coordinate transformations. A detailed explanation of used algorithms and criteria is out of the scope of the e-learning course. Nevertheless, some short explanation with references is a part of the course. Following example shows a part of an output file from the detectproj applied on the map "Europe Politique" from the Atlas St. Cyr. Furne edited by Jouvet et Cie in 1882 that was created in Bonne projection (Figure 3).

\section{Conclusion}

The presented e-learning course provides learning materials from two different fields, bibliography and geoinformatics, and it is in the first place intended to help and to train personnel from institutions dealing with digitizing and cataloguing map collections. According to the knowledge of the authors such a course is not available on-line yet. Gathering metadata and 

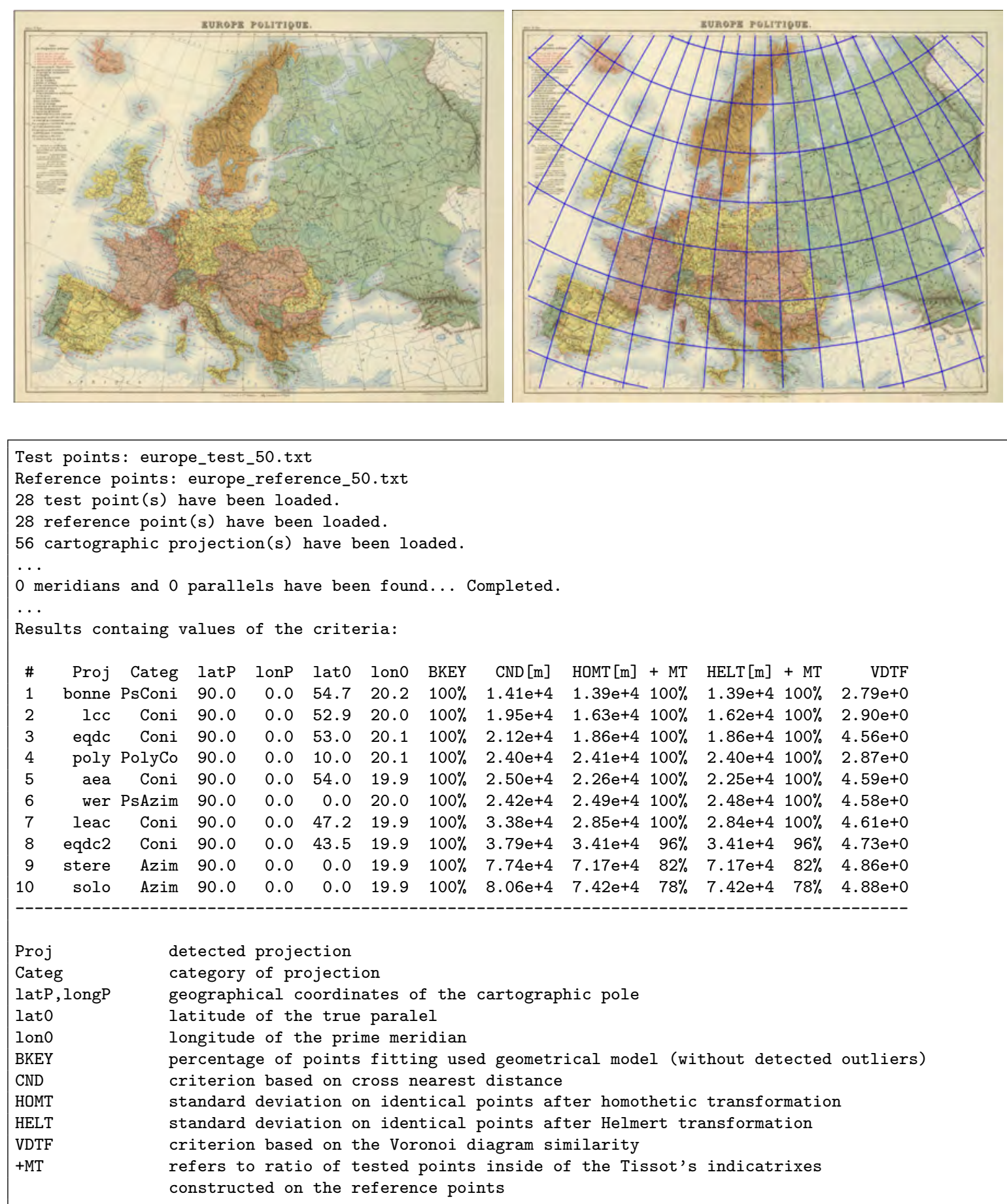

Figure 3: Detection of a projection applied on the map "Europe Politique" from the Atlas St. Cyr. Furne edited by Jouvet et Cie in 1882 (David Rumsey Map Collection [4]). The upper part of the figure shows an overview of an original map (left) and the graticule of the detected Bonne projection (right). The text bellow is a subset of the detectproj software output file supplemented with an explanation of abbreviations of selected criteria. 
georeferencing of old maps is a tedious and expensive work. Crowdsourcing of this process seems to be a meaningful solution as the pilots from the UK have shown [23]. In this case the course can help to those volunteers who have a deeper interest in cartography. The course can possibly guide them so the obtained metadata will be more reliable. Moreover, the course will support lectures in cartographic subjects such as History of cartography that are a part of curricula of the master degree in Cartography and Geoinformatics at Charles University in Prague. The described contents of the e-learning course is now being implemented in the Moodle learning management system running on the server of Charles University [29]. During 2013 the Czech version will be completed and its English counterpart is going to be finished a year after.

\section{Acknowledgement}

Development of the presented e-learning course is done with the support of the Ministry of Culture of the Czech Republic, Nr. DF11P01OVV003: TEMAP: Technology for access to Czech map collections: methodology and soft ware for protection and re-use of national cartographic heritage.

\section{References}

[1] 5th International Workshop on Digital Approaches in Cartographic Heritage in Vienna, February 22-24, 2010, http://cartography.tuwien.ac.at/cartoheritage/

[2] Gartner, G., Ortag, F. (Eds.): Cartography in Central and Eastern Europe, Springer Verlag Berlin Heidelberg 2010, ISBN 978-3-642-03294-3.

[3] Liebenberg, E., Demhardt, I. J. (Eds.): History of Cartography, Springer Verlag Berlin Heidelberg 2012, ISBN 978-3-642-19087-2

[4] David Rumsey Map Collection, http://www.davidrumsey.com/

[5] AFRITERRA Cartographic Library and Archive, http://www.afriterra.org/

[6] Moll's Map Collection, the Moravian Library, http://mapy.mzk.cz/en/mollova-sbirka/

[7] MapRectifier, http://labs.metacarta.com/rectifier/

[8] WorldMap WARP, http://warp.worldmap.harvard.edu/

[9] eHarta, http://earth.unibuc.ro/articole/eHarta?lang=en

[10] Georeferencer http://www.georeferencer.org/

[11] MapAnalyst, http://mapanalyst.org/

[12] Workshop on Archiving in Digital Cartography and Geoinformation, Berlin, Germany, December 4-5, 2008, http://www. codata-germany.org/Archiving_2008/

[13] ICA Commission on digital technologies in cartographic heritage, http://xeee.web. auth.gr/ICA-Heritage/

[14] International Conference: Historic maps and imagery for modern scientific applications II, Bern, October 1-3, 2009, http://maps .unibe.ch/2009.html 
[15] Moodle learning management system, https://moodle.org/

[16] Žabička, P., Přidal, P., Konečný, M., Novotná, E.: TEMAP : technology for discovering of map collections. Poster. In.: 15. International conference of historical geographers. Prague : Charles University, Faculty of Science, August 6.-10., 2012.

[17] Boutoura, C., Livieratos, E.: Some fundamentals for the study of the geometry of early maps by comparative methods, e-Perimetron, Vol.1, No. 1, Winter 2006, http://www . e-perimetron.org/Vol_1_1/Boutoura_Livieratos/1_1_Boutoura_Livieratos.pdf

[18] OpenLayers, http://openlayers.org/

[19] Tile Map Service specification, http://wiki.osgeo.org/wiki/Tile_Map_Service_ Specification

[20] Zoomify technology, http://www.zoomify.com/

[21] Přidal, P., Žabička, P.: Tiles as an approach to on-line publishing of scanned old maps, vedute and other historical documents, e-Perimetron, Vol. 3, No. 1, 2008, http://www.e-perimetron.org/Vol_3_1/Pridal_Zabicka.pdf

[22] Spherical Mercator projection, http://trac.osgeo.org/openlayers/wiki/SphericalMercator

[23] Kowal, K. C., Přidal, P.: Online Georeferencing for Libraries: The British Library Implementation of Georeferencer for Spatial Metadata Enhancement and Public Engagement, Journal of Map \& Geography Libraries: Advances in Geospatial Information, Collections \& Archives, 8:3,2012, pp. 276-289

[24] Bayer, T., Potůčková, M., Č́belka, M.: Kartometrická analýza starých map českých zemí: mapa Čech a mapa Moravy od Petra Kaeria. In: Geografie - Sborník České geografické společnosti 2009/3, s. 230-243, ISSN 1212-0014.

[25] Bayer, T., Potůčková, M., Čábelka, M.: Cartometric Analysis of old maps on example of Vogt's Map. In: ICA Symposium on Cartography for Central and Eastern Europe, LNG\&C, pp 509-522, Vienna, Springer, 2009, ISBN: 978-3-642-03293-6.

[26] Jenny, B., Hurni, L.: Studying cartographic heritage: Analysis and visualization of geometric distortions, Computers \& Graphics 35 , 2011, pp. 402-411

[27] DetectProj software and manual, http://web.natur.cuni.cz/ bayertom/software.html

[28] Proj.4 library, http://trac.osgeo.org/proj/

[29] Moodle - Charles University in Prague, http://dl2.cuni.cz/ 